\title{
Perinatal death beyond 41 weeks pregnancy: an evaluation of causes and substandard care factors as identified in perinatal audit in the Netherlands
}

Joep C. Kortekaas ${ }^{1,2^{*}}$ D, Anke C. Scheuer ${ }^{1}$, Esteriek de Miranda², Aimée E. van Dijk ${ }^{3}$, Judit K. J. Keulen², Aafke Bruinsma², Ben W. J. Mol ${ }^{4}$, Frank P. H. A. Vandenbussche ${ }^{1}$ and Jeroen van Dillen ${ }^{1}$

\begin{abstract}
Background: Late- and postterm pregnancy are associated with adverse perinatal outcomes, like perinatal death. We evaluated causes of death and substandard care factors (SSFs) in term and postterm perinatal death.

Methods: We used data from the Perinatal Audit Registry of the Netherlands (PARS). Women with a term perinatal death registered in PARS were stratified by gestational age into early-/full-term (37.0-40.6) and late-/postterm ( $\geq 41.0$ weeks) death. Cause of death and SSFs $\geq 41$ weeks were scored and classified by the local perinatal audit teams.

Results: During 2010-2012, 947/479,097 (0.21\%) term deaths occurred, from which 707 cases (75\%) were registered and could be used for analyses. Five hundred ninety-eight early-/full-term and 109 late-/postterm audited deaths were registered in the PARS database. Of all audited cases of perinatal death in the PARS database, $55.2 \%$ in the early-/ fullterm group occurred antepartum compared to $42.2 \%$ in the late-/postterm group, while intrapartum death occurred in $7.2 \%$ in the early-/full-term group compared to $19.3 \%$ in the late-/postterm group in the audited cases from the PARS database. According to the local perinatal audit, the most relevant causes of perinatal death $\geq 41$ weeks were antepartum asphyxia (7.3\%), intrapartum asphyxia (9.2\%), neonatal asphyxia (10.1\%) and placental insufficiency (10.1\%). In the group with perinatal death $\geq 41$ weeks there was $\geq 1$ SSF identified in $68.8 \%$. The most frequent SSFs concerned inadequate cardiotocography (CTG) evaluation and/or classification (10.1\%), incomplete registration or documentation in medical files (4.6\%) or inadequate action on decreased foetal movements (4.6\%).

Conclusions: In the Netherlands Perinatal Audit Registry, stillbirth occurred relatively less often antepartum and more often intrapartum in pregnancies $\geq 41$ weeks compared to pregnancies at 37.0-40.6 weeks in the audited cases from the PARS database. Foetal, intrapartum and neonatal asphyxia were identified more frequently as cause of death in pregnancies $\geq 41$ weeks. The most identified SSFs related to death in pregnancies $\geq 41$ weeks concerned inadequate CTG monitoring (evaluation, classification, registration or documentation) and inadequate action on decreased foetal movements.
\end{abstract}

Keywords: CTG, Delivery, Foetal monitoring, Late-term pregnancy, Mortality, Postterm pregnancy, Pregnancy, Stillbirth

\footnotetext{
*Correspondence: joep.kortekaas@radboudumc.nl

'Department of Obstetrics and Gynaecology, Radboud University Medical Center, Geert Grooteplein Zuid 10, 6523, GA, Nijmegen, the Netherlands

${ }^{2}$ Department of Obstetrics and Gynaecology, Amsterdam University Medical Centers, Amsterdam, the Netherlands

Full list of author information is available at the end of the article
}

(c) The Author(s). 2018 Open Access This article is distributed under the terms of the Creative Commons Attribution 4.0 International License (http://creativecommons.org/licenses/by/4.0/), which permits unrestricted use, distribution, and reproduction in any medium, provided you give appropriate credit to the original author(s) and the source, provide a link to the Creative Commons license, and indicate if changes were made. The Creative Commons Public Domain Dedication waiver (http://creativecommons.org/publicdomain/zero/1.0/) applies to the data made available in this article, unless otherwise stated. 


\section{Backgound}

The incidence of postterm pregnancies ( $\geq 42.0$ weeks) in European countries varies from $0.5 \%$ (Austria/Belgium) to 9\% (Denmark/Sweden), depending on accurate pregnancy dating and clinical management protocols [1-5]. Ongoing pregnancy from 41 weeks onwards is associated with an increased risk of perinatal death and morbidity although the absolute risk of perinatal death is low [2, 6-8]. In the Perinatal Registry Netherlands (PRN), 534,058 births were registered between 2010 and 2012; 380,252 singletons were born between 37.0-40.6 weeks and 98,845 were born $\geq 41.0$ weeks of gestation. The overall perinatal mortality rate in term and postterm singleton births per ongoing pregnancy in the gestational age interval was $0.20 \%$ (947/ $479,097)$. In the early-/full-term pregnancy (37.0-40.6) a perinatal mortality rate of $0.21 \%(787 / 380,252)$ was found and $0.16 \%(160 / 98,845)$ in pregnancies $\geq 41.0$ weeks [9].

Controversy about the clinical management of an uncomplicated pregnancy reaching 41 weeks concerns the question whether labour should be induced at 41.0 weeks or if expectant management until 42.0 weeks could be allowed considering the prevention of adverse perinatal outcomes such as perinatal death $[1,4,6,10,11]$. In the Netherlands, this question has been identified by Dutch midwives and gynaecologists as the main dilemma in obstetrical policy in the term period resulting in the INDEX trial: a randomised clinical trial in which effects and costs of both induction of labour at 41.0 weeks and expectant management until 42.0 weeks are studied [12].

The aim of this perinatal audit study was to gain more insight into perinatal death in early-/full- (37.0-40.6 weeks) and late-/postterm ( $\geq 41.0$ weeks) pregnancies by analysing the causes of death. A second goal of this study was to describe substandard care factors (SSFs) of all audited perinatal deaths at or beyond 41 weeks of gestation.

\section{Methods}

A quantitative descriptive study was conducted on data from the Perinatal Audit Registry System (PARS) from 2010 to 2012. No ethical approval was needed according to the Dutch Central Committee of Human Research, because it concerns a study with anonymous data.

\section{Aim, design and setting of the study}

All birth outcomes, including death, in pregnancies with a delivery of $\geq 22.0$ weeks of gestation are anonymously entered in the Perinatal Registry Netherlands (PRN). A nationwide perinatal mortality audit was introduced in the Netherlands in 2010 by the foundation Perinatal Audit in the Netherlands (PAN) $[9,13]$. Perined, a merger of PAN and the PRN, manages three web-based databases with anonymous (information not traceable to individual patients) registration on case level: the PRN, the Perinatal Audit Registry of the Netherlands (PRN-audit) and PARS. Cases of perinatal death are registered in the PRN audit. After registration, an anonymous narrative of each case is automatically constructed for use in the local perinatal audit. The aim to audit all cases of perinatal death was not always fulfilled. Based on content, some cases are selected by the local team to evaluate in the local perinatal audit. For example, cases can be chosen based on impact of the case on the obstetric caregivers involved, to stimulate modifications in local obstetric care to prevent future cases or because cases contain a rare event which can be informative to any obstetric caregiver. Cases are then evaluated by a multidisciplinary team, consisting of gynaecologists, midwives, paediatricians, general practitioners, and nurses, using the format of the local perinatal audit. In the local perinatal audit, the quality of perinatal care, the cause of the perinatal deaths, and the presence of SSFs are identified and systematically and critically analysed [14-16]. Time of death is determined by using the Wigglesworth/Hey classification $[17,18]$. Cause of death is determined by using the modified relevant condition of death (ReCoDe). The modified ReCoDe was created by PAN and contains the ReCoDe of Gardosi added with the neonatal classification of Chan and maternal risk factors $[19,20]$. On each case, more than one clinical condition can be chosen as cause of death and in each case one item with the 'most important relation to death' is chosen. A detailed handbook for definition and classification was distributed to each local perinatal audit team [21]. The results of the audit process are registered in PARS by a trained representative of each local perinatal audit team $[17-19,22,23]$. Data used for this study originated from the registered cases of perinatal death in PARS. Details about the organisation and training of care providers participating in the Perinatal Audit is described by Eskes [23].

\section{Characteristics of participants}

Based on the Wigglesworth/Hey classification (WHEN) all perinatal deaths of $\geq 37$ weeks in the PARS registry could be selected. A comparison could be made between early-/full-term pregnancy (37.0-40.6 weeks of pregnancy) and late-/postterm pregnancy ( $\geq 41$ weeks). Unfortunately, discrimination between the late-term and postterm group was not possible in the PARS registry, only a group $\geq 41$ weeks could be selected.

\section{Description of processes, interventions and comparisons}

A handbook for definition and classification of perinatal death was distributed to each local perinatal audit team. Stillbirth is defined as all antepartum and intrapartum stillbirth combined. Neonatal death is specified as all deaths after livebirth until 28 days and is divided in early (day 0-6) and late (day 7-27). Foetal asphyxia is defined as pathological changes caused by lack of oxygen, resulting in hypoxia and hypercapnia. Intrapartum asphyxia is 
defined as evidence of severe hypoxemia after the onset of labour, in the presence of contractions [21]. To determine foetal well-being before or during labour, foetal cardiac rhythm is monitored either by doptone (low risk pregnancies in midwifery-led care) or by cardiotocography (CTG, high risk pregnancies in obstetrician-led care). Severe CTG abnormalities are used in the modified ReCoDe as a proxy for foetal hypoxia [21].

The main outcomes of a local perinatal audit concerns SSFs and recommendations. In each discussed case, all possible SSFs are collected by the local perinatal audit team, entered in PARS and used to change practice in order to prevent future SSFs of the same type. At the next local perinatal audit, the SSFs from the previous audit are presented to all present obstetric caregivers. The aim of this process is to improve the quality of care. For each perinatal death, multiple SSFs could be entered in free description fields. An SSF was defined as "a care management problem involving care that deviated from the safe limits of practice as laid down in guidelines, standards, protocols or normal practice" [23-25]. The category 'guidelines' is used to describe deviations from care as laid down in documents on practice/management by obstetric caregivers. The category 'usual care' is used for what is considered as standard acts of care by professional caregivers. The subclassifications of 'usual care' for this study were based on examples from Eskes et al. and from a national report on term perinatal mortality audit $[9,23]$. The probability that the SSF was related to the cause of death was subdivided into: very likely, likely, possible, indeterminable, unlikely, none, and no consensus. The cases in the groups very likely, likely and possible were analysed to examine the SSF's relation to the cause of death. In line with the INDEXstudy, we selected data of the SSFs in perinatal deaths beyond 41 weeks of gestation. For this reason, we did not make a comparison with SSFs in the early-/full-term pregnancy period.

\section{Statistics}

Descriptive statistics were used to describe differences between early-/full-term and the late-/postterm group and to describe SSFs in perinatal deaths in pregnancies of 41 weeks and beyond. No statistical analyses were performed, due to the rare occurrence of the outcome, the content of data and the design of the study.

\section{Results}

Between 2010 and 2012, 947 perinatal deaths in pregnancies of $\geq 37.0$ were registered in the PARS database. From these registered deaths, 925 (98\%) were audited and 707 (75\%) were registered in PARS, from which 8 with an 'unknown' timing of death [9, 26-28]. No extra information could be obtained from the 218 (24\%) perinatal deaths that were not registered in PARS (Fig. 1). Based on the
Wigglesworth/Hey classification (WHEN), it was possible to stratify $598 / 787$ (76\%) registered perinatal deaths to the early-/full-term group (37.0-40.6) and 109/153 (71\%) to the late-/postterm group ( $\geq 41.0)$ (Fig. 1). Stratified by moment of death we could identify 440 stillbirths and 259 neonatal deaths (Table 1). Antepartum stillbirth was registered in $55.2 \%$ in the early-/full-term group and in $42.2 \%$ in the late-/postterm group. Intrapartum stillbirth was registered $7.2 \%$ in the early-/full-term group and in $19.3 \%$ the late - /postterm group.

In Table 2, the most common classification of perinatal death (Modified ReCoDe) is shown, as determined by the local perinatal audit, stratified by gestational age and subdivided by congenital anomalies. Foetal congenital anomalies were found in $15 \%$ in the early-/full-term group and in $4 \%$ in the late-/postterm group. In foetus/neonates without congenital anomalies, foetal asphyxia occurred in $19 \%$ of the early-/full-term group in comparison to $33 \%$ in the late-/postterm group. Intrapartum asphyxia occurred in $16 \%$ in the early-/full-term group and 34\% in the late-/postterm group (Table 2). Acute infections, neonatal asphyxia and $\mathrm{BMI} \geq 25 \mathrm{~kg} / \mathrm{m}^{2}$ are less often classified as reason of death in the early-/full-term group in comparison to the late-/postterm group. In 16 cases, both foetal asphyxia and intrapartum asphyxia were selected by the local perinatal audit in the same case.

The most frequent, most relevant condition causing death in the full late-/postterm group according to the local perinatal audit was foetal asphyxia in 63/109 (57.8\%), intrapartum asphyxia in 9.2\% (10/109), neonatal asphyxia in $10.1 \%(11 / 109)$ and placental insufficiency in $10.1 \%(11 / 109)$ (Fig. 2).

A total of 178 SSFs were identified in 109 cases of perinatal death in pregnancies of 41 weeks and beyond. In 75 cases (68.8\%), at least one or more SSFs could be identified (Table 3). There were no differences in number of cases with SSFs across 2010-2012. In 63/178 (35.4\%) cases, SSFs were identified as a very likely, likely and possible relation to the cause of death. The most frequent reported SSFs in this group concerned 'CTG evaluation and classification' in $11 / 109$ (10.1\%), 'CTG registration or documentation' in 5/109 (4.6\%) and 'inadequate management in reduced foetal movements' in 5/109 (4.6\%).

\section{Discussion}

Main findings

Perinatal death in term- and postterm pregnancy is rare. In our study, stillbirth occurred less often antepartum and more often intrapartum in pregnancies $\geq 41.0$ weeks in comparison to pregnancies at 37.0-40.6 weeks. Asphyxia was seen more frequently as the most relevant condition causing death in pregnancies $\geq 41.0$ weeks. Substandard factors with a likely relation to death in pregnancies $\geq 41.0$ weeks concerned inadequate CTG 


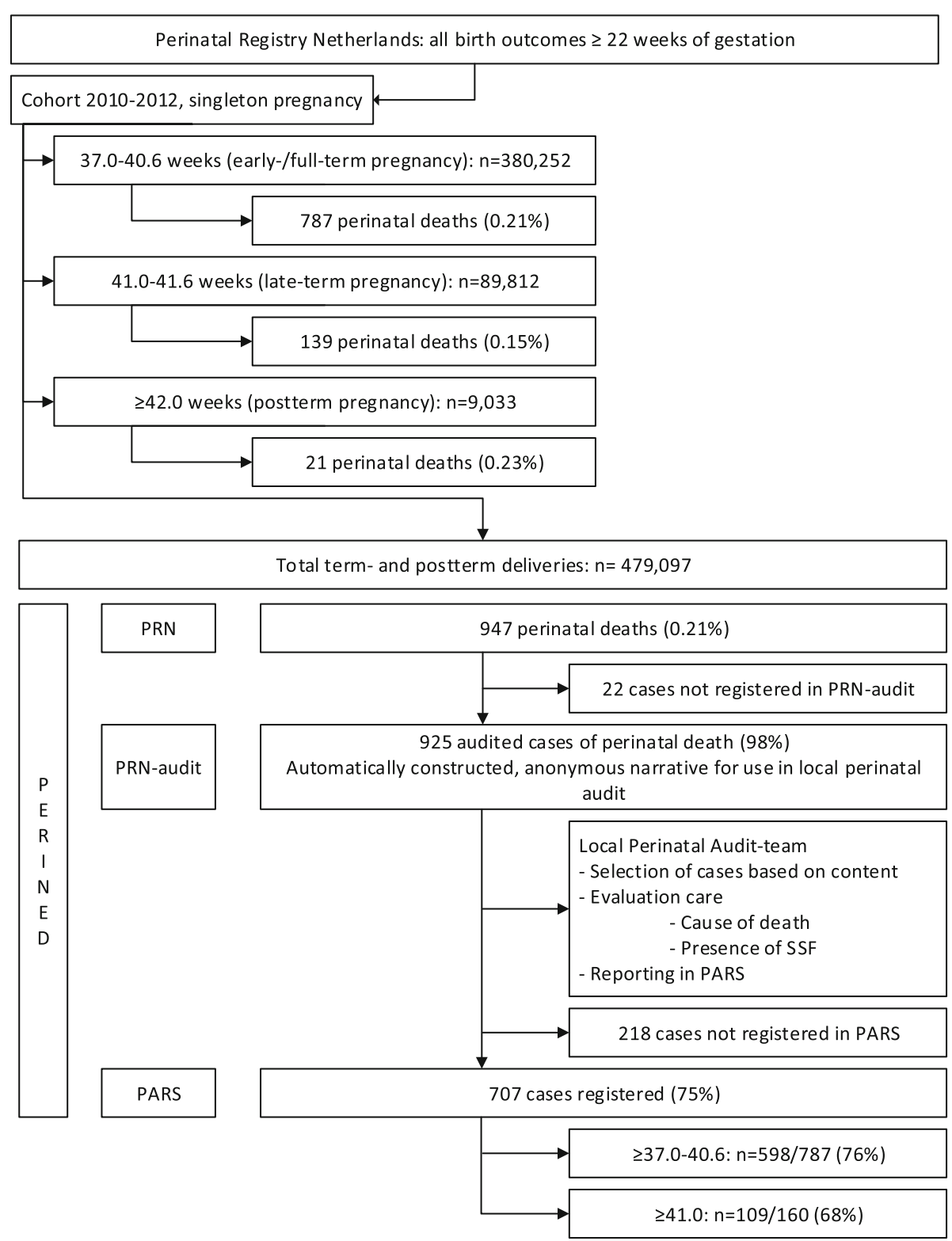

Fig. 1 Flowchart of selection of cases of perinatal death $\geq 37$ weeks between 2010 and 2012 Perinatal Registry Netherlands 2010-2012: all birth outcomes in pregnancies $\geq 22$ weeks of gestation

Table 1 Term stillbirth and neonatal death stratified by gestational age registered in the Dutch Perinatal Audit system

\begin{tabular}{|c|c|c|c|c|c|c|c|c|c|c|c|}
\hline \multirow{3}{*}{$\begin{array}{l}\text { Gestational } \\
\text { age (wk) } \\
\geq 37.0-40.6(n, \%)\end{array}$} & \multicolumn{4}{|c|}{ Stillbirth $(n=440)$} & \multicolumn{4}{|c|}{ Neonatal death $(n=259)$} & \multirow{2}{*}{\multicolumn{2}{|c|}{ Missing }} & \multirow[t]{2}{*}{ Total } \\
\hline & \multicolumn{2}{|c|}{ Antepartum } & \multicolumn{2}{|c|}{ Intrapartum } & \multicolumn{2}{|c|}{ Early (day 0-6) } & \multicolumn{2}{|c|}{ Late (day 7-27) } & & & \\
\hline & 330 & $55.2 \%$ & 43 & $7.2 \%$ & 166 & $27.8 \%$ & 51 & $8.5 \%$ & 8 & $1.3 \%$ & 598 \\
\hline$\geq 41.0(n, \%)$ & 46 & $42.2 \%$ & 21 & $19.3 \%$ & 31 & $28.4 \%$ & 11 & $10.1 \%$ & & & 109 \\
\hline Total (n, \%) & 376 & $53.2 \%$ & 64 & $9.1 \%$ & 197 & $27.9 \%$ & 62 & $8.8 \%$ & 8 & $1.1 \%$ & 707 \\
\hline
\end{tabular}

See Fig. 1 for national cases of term perinatal death between 2010 and 2012 
Table 2 Most common classification of perinatal death (Modified ReCoDe) stratified by gestational age

\begin{tabular}{|c|c|c|c|c|c|}
\hline \multirow[t]{2}{*}{ Classification } & \multirow[t]{2}{*}{ Subclassification } & \multicolumn{2}{|c|}{ 37.0-40.6 weeks (ref) } & \multicolumn{2}{|c|}{$\geq 41$ weeks } \\
\hline & & $\mathrm{N}$ & $\%$ & $\mathrm{~N}$ & $\%$ \\
\hline Overall & & 598 & & 109 & \\
\hline Foetal/antepartum & Congenital anomaly & 89 & $15 \%$ & 4 & $4 \%$ \\
\hline Neonatal & Congenital anomaly & 104 & $17 \%$ & 8 & $7 \%$ \\
\hline \multicolumn{2}{|c|}{ Without congenital anomalies } & 441 & & 97 & \\
\hline \multirow[t]{2}{*}{ Foetal/antepartum } & Infection: acute & 13 & $3 \%$ & 8 & $8 \%$ \\
\hline & Asphyxia $^{a}$ & 82 & $19 \%$ & 32 & $33 \%$ \\
\hline Neonatal & Asphyxia & 63 & $14 \%$ & 20 & $21 \%$ \\
\hline Maternal & Risk factor: overweight (BMI $\geq 25$ ) & 100 & $23 \%$ & 33 & $34 \%$ \\
\hline Intrapartum & Asphyxia $^{a}$ & 70 & $16 \%$ & 33 & $34 \%$ \\
\hline
\end{tabular}

${ }^{a} 16$ cases of perinatal death are registered in both foetal asphyxia and in intrapartum asphyxia

For each case $\geq 1$ condition could be entered

monitoring (evaluation, classification, registration or documentation) in $14.7 \%(16 / 109)$ and 'reduced foetal movements in $4.6 \%$.

\section{Validity of the results}

This nationwide study shows an audited cohort regarding the perinatal mortality in the Netherlands. Of the late -/postterm perinatal deaths, 68\% (109/160) were registered in PARS, which is comparable to the $76 \%(598 / 787)$ of the early-/full-term registered perinatal deaths [2628]. It was described in the study of Eskes et al. that -although not all term cases of perinatal death are audited-characteristics of the audited cases like parity, maternal age, and gestational age, are comparable with all term perinatal deaths in the national registration of the Netherlands Perinatal Registry (PRN) [23]. We assume that this statement also applies on our cohort, since we have used the same source of data, though comparisons with other studies should be made keeping this selection of cases in mind.

Audit teams auditing perinatal care is becoming more and more part of common care, with the aim to reduce perinatal mortality and improve the quality of care at all levels of the health system [29-32]. Efforts to prevent perinatal and maternal deaths will improve perinatal and maternal outcomes, which are markers of the quality of care in pregnancy and childbirth, also in high-income countries [33, 34].

Eskes et al. assessed the implementation and the results of the Perinatal Audit in 2010-2012 of pregnancies $\geq 37$ weeks in the Netherlands using PARS data. They showed that total stillbirth in the early-/full-term period was comparable to the late-/postterm period, without making the sub-classification in ante- and intrapartum stillbirth like shown in our study [23].

There are different ways to describe perinatal and maternal death [35]. Perined uses Wigglesworth/Hey and

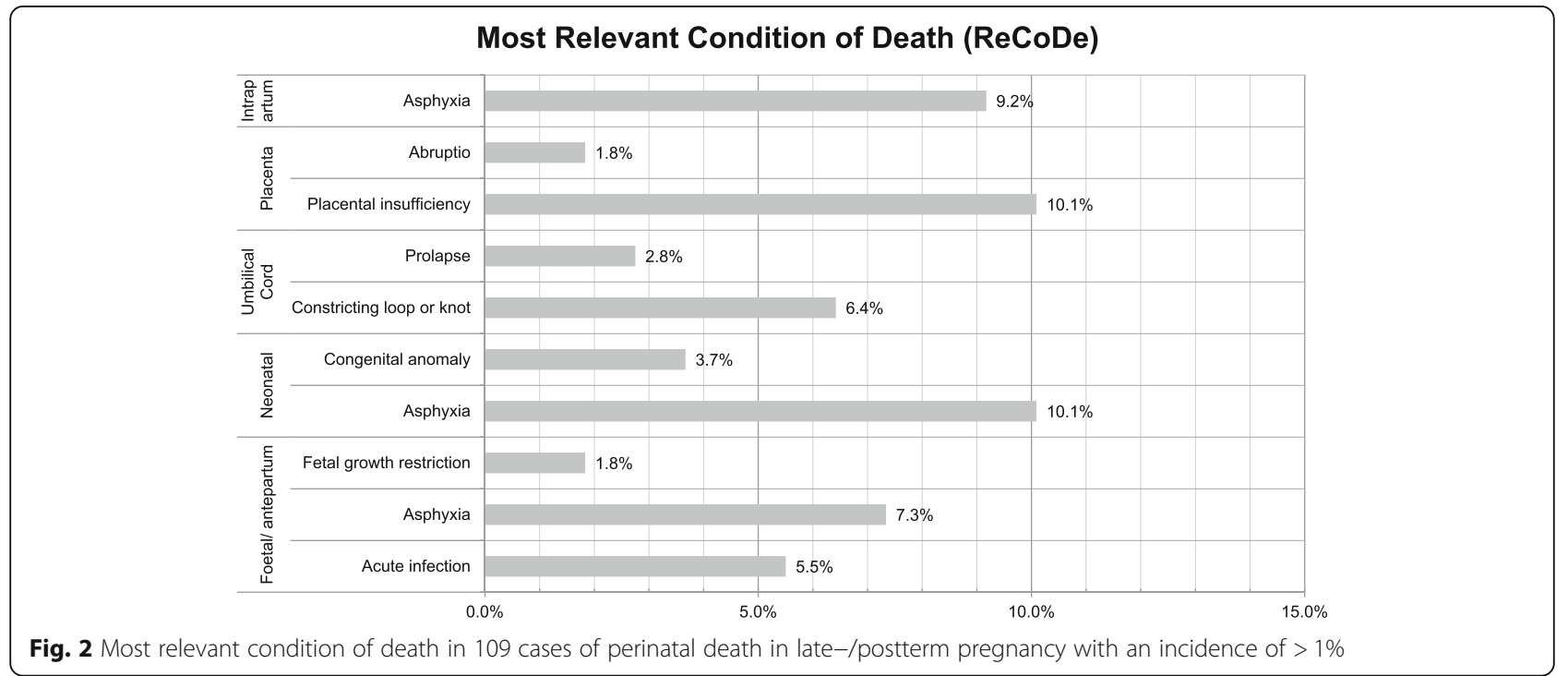


Table 3 Number and content of substandard care factors (SSF) per perinatal death case $\geq 41$ weeks as identified by the local perinatal audit

\begin{tabular}{lll}
\hline & $\mathrm{n}$ & $\%$ \\
\hline Cases of perinatal death & 109 & \\
$\geq 1$ SSF & 75 & $68.8 \%$ \\
1 SSF & 29 & $38.7 \%$ \\
2 SSF & 14 & $18.7 \%$ \\
3 SSF & 17 & $22.7 \%$ \\
$\geq 4$ SSF (max 8) & 15 & $20.0 \%$ \\
No SSF & 27 & $24.8 \%$ \\
Missing/insufficient data & 7 & $6.4 \%$ \\
SSF with possible/ likely/ very likely relation to death & \\
Guideline- oriented SSF & 63 & $57.8 \%$ \\
Cardiotocography evaluation or classification & & \\
Cardiotocography registration or documentation & 5 & $4.6 \%$ \\
Guideline obesity & 3 & $2.8 \%$ \\
Usual Care- oriented SSF & & \\
Midwifery guidelines & 4 & $3.7 \%$ \\
Documentation in the medical records & 3 & $2.8 \%$ \\
Decreased foetal movements & 5 & $4.6 \%$ \\
Patient factor & 3 & $2.8 \%$ \\
Total number SSF & 178 & \\
\hline
\end{tabular}

anknown/unclear cases are not presented

the modified ReCoDe to determine timing and cause of death [21]. Internationally, the ICD-PM is often used to describe deaths during the perinatal period and is based on the coding rules of the ICD-10 (International Statistical Classification of Diseases and Related Health Problems) and allows comparisons of perinatal death between settings) [36, 37]. The ICD-PM first codes the timing of death (antepartum, intrapartum or neonatal) and is comparable to the Wigglesworth/Hey. Secondly, ICD-PM assigns the main cause of perinatal death, which is comparable to the modified ReCoDe we used. Lastly, ICD-PM assigns the main maternal condition at the time of perinatal death, which is also part of the classification by Perined. Although both classification systems are broadly comparable, Perined should be advised to introduce ICD-PM for future studies and to be able to compare with international data.

When using term singleton deliveries registered in the PRN, the proportion of perinatal death is lowest $(0.15 \%)$ in the late-term pregnancy period (41.0-41.6), $0.21 \%$ in the early-/full term period and $0.23 \%$ in the postterm pregnancy period. In the PRN data, the proportion of foetal death $(0.14 \%$ vs $0.11 \%)$ and neonatal death $(0.07 \%$ vs $0.06 \%$ ) is slightly higher in the early-/full-term group in comparison to the late- and postterm group. When using the selected cases of perinatal deaths from the PARS database, the proportion of stillbirth exceeds the proportion of neonatal mortality in both the early-/fullterm group and the late-/postterm group. The systematic review of Gulmezoglu on induction of labour in women at or beyond term, showed no differences in timing of induction regarding perinatal death [6]. Our results are in concordance with the observations of Mandujano et al., who analysed more than 8 million pregnancies in 2003-2005 in the US, showing that at 37-38 weeks of gestation the number of neonatal deaths is lower than the level of stillbirths [38]. Our results are in contrast with the results of Rosenstein et al., who analysed nearly 4 million pregnancies in 1997-2006 in the state of California, showing that the proportion of infant death (defined as number of children who died in the first year of live) exceeds the proportion of stillbirths in the term period in all ethnicities [39]. This difference could be due to a pregnancy dating based on last menstrual period instead of early ultrasound and we were only able to analyse data on perinatal death during the first month instead of the first year. In a Swedish cohort study from 1982 to 1991, the stillbirth rate was highest for primiparas at 38 completed weeks $(0.27 \%)$, lowest at 40 weeks $(0.12 \%)$, and $0.23 \%$ in the postterm period [8]. All mentioned studies concern other methods of pregnancy dating and other timeframes than our study which makes a clear comparison difficult.

In our Perinatal Audit study, foetal and intrapartum asphyxia was identified more in the late-/postterm death group than in the early-/full-term group in the present study. In 16 cases, both foetal and intrapartum asphyxia was selected in the ReCoDe. In some cases, it could be hard to differentiate whether the pathological process of asphyxia started before or during labour. If antepartum asphyxia occurred, this process would most probably continue throughout labour, which could have contributed to the double selection in ReCoDe. Hereby, we could have both over- and underestimated the proportion of foetal and intrapartum asphyxia. The placental function is presumably the most important factor contributing to asphyxia in general and to asphyxia in foetal growth restriction [40, 41]. Regarding intrapartum asphyxia, Berglund et al. reported a threefold increased risk for asphyxia in postterm deliveries compared to term deliveries [42]. In postterm pregnancy, labour is induced and monitored by CTGevaluation, which is the most important SSF in our audit reports. When labour is induced, there is a risk of hyperstimulation which, if not recognised, could contribute to asphyxia. In late -/postterm pregnancy, one of the most important risk factors associated with increased perinatal mortality is foetal growth restriction $[43,44]$ However, in the present study foetal growth restriction was classified as most important reason of death in $1.8 \%$ and classified as 'relevant'in $6.4 \%$. This difference in incidence could be due to the way data was entered: Asphyxia is considered a more contributing 
factor to perinatal death than growth restriction resulting in a higher registration of this risk factor. Also, at suspected growth restriction, most women are induced at 40 weeks, resulting in a lower overall incidence [44].

There is no uniform international standardisation of SSFs categories and definitions, making it difficult to compare the results of studies with each other and with our present study. The possibility to compare with other studies would help us to learn from SSFs demonstrated by others, keeping in mind the level of development of obstetric care in each country. In the EuroNatal study, 1619 cases of perinatal death $\geq 28$ weeks were analysed in an external audit. SSFs with a possible or probable relation to death were found in $46 \%$ of the cases. [15] In 63/109 (57.8\%) of the cases in this study an SSF with a very likely, likely or possible relation to death was found. According to the EuroNatal results, the most important SSF was undetected foetal growth restriction and in 10\% it was seen as a cause that might have or was likely to have contributed to death [15].

In our study, the main reason for an SSF with a relation to death, were inadequate CTG evaluation or classification in $11 / 109(10.1 \%)$ and registration or documentation in $5 /$ 109 (4.6\%). Berglund et al. performed a case-control study in which neonates with and without an Apgar score of $<7$ at 5 min were compared regarding substandard care during labour. The main finding of substandard care was "misinterpretation of CTG, not acting on an abnormal CTG in a timely fashion and incautious use of oxytocin" [45]. In an earlier study of Berglund et al., staff did not act timely on pathological CTGs in $71 \%$ of the pregnancies [46]. In a study by Batlle et al., in which the quality of intrapartum care regarding birth asphyxia was assessed, two of the main shortcomings were related to misinterpretation of CTG and a delayed response time to CTG anomalies [47]. Auditing cases of perinatal death/asphyxia often classifies a CTG as non-reassuring in retrospect, while it is known that there is a poor inter-observer agreement on classification and management on non-reassuring CTGs [48]. These studies, as well as the present study, show the importance of adequate execution of CTG monitoring to reduce substandard care and to improve birth outcome.

\section{Strengths and limitations}

The perinatal audit was not primarily set up for scientific purposes, but as an instrument to monitor and improve the quality of perinatal healthcare. Because PARS is set up as an anonymous database it was not possible to link the data to the national perinatal registry or check the source files, resulting in missing maternal and perinatal information on case level. Especially the impossibility to distinguish between late-term and postterm pregnancy, parity, level of care during pregnancy and delivery, onset of labour (spontaneous onset or labour induction) and mode of delivery are major limitations of the current PARS registry. This makes it difficult to draw conclusions on the level of obstetric management and is the main reason we did not perform statistical analyses $[9,13,23]$. Another limitation is that only $75 \%$ of all cases are audited and entered in PARS. Cases with a clear cause of death are sometimes not audited, which results in a selected group of perinatal deaths registered in PARS and could contribute to an over-/underestimation in timing of perinatal death, causes of perinatal death and SSFs. Though auditing cases of maternal/perinatal/adverse events is getting more and more 'standard care', it is still not obligatory to perform an audit, or to enter audited cases in the PARS database. This reflection on management of care could be a quality requirement to ensure high standards in obstetric care in the Netherlands.

A limitation of the SSF classification system is that this is not standardized, which makes it more difficult to compare our results to other countries. The main outcome regarding inadequate CTG monitoring could not be differentiated into monitoring prior or during delivery.

\section{Recommendations}

There is an urgent need for a uniform international classification system of SSFs. The Groningen system has a moderate to good inter-rater agreement on well-defined (sub) categories, with clear guidelines and examples, which can be used to standardise the SSFs in the PARS database together with the studies of Eskes [49]. In addition, the PARS database should also make some basic characteristics and obstetric characteristics (eg spontaneous onset of labour/induction) obliguatory to fill in and use the ICD-PM classification in order to make the database more suitable for future evaluation. Finally, in pregnancies $\geq 41$ weeks, care providers should be aware of the risk of intrapartum asphyxia and in those pregnancies where CTG is indicated, attention should be paid to adequate CTG registration, evaluation and classification.

\section{Conclusions}

Pregnancies with a gestational age at or beyond 41 weeks, from which $75 \%$ registered in the Dutch Perinatal Audit system, showed less antepartum stillbirth and more intrapartum stillbirth than pregnancies of 37.0-40.6 weeks. More foetal, intrapartum, and neonatal asphyxia were identified as causes of death in pregnancies beyond 41 weeks compared to pregnancies of 37.0-40.6 weeks. The most identified SSFs with a relation to death in pregnancies beyond 41 weeks concerned inadequate CTG monitoring (evaluation, classification, registration or documentation) and 'inadequate action on decreased foetal movements'. 


\section{Abbreviations}

CTG: Cardiotocography; PAN: Perinatal Audit in the Netherlands (now Perined); PARS: Perinatal Audit Registry System; PRN: Perinatal Registry Netherlands (now Perined); ReCoDe: Relevant Condition of Death; SSFs: Substandard care factors

\section{Acknowledgments}

We would like to thank all members of the local perinatal audit who contributed in entering data in PARS.

\section{Availability of data and materials}

All authors had full access to the data and materials. The data that support the findings of this study are available from Perined but restrictions apply to the availability of these data, which were used under license for the current study, and so are not publicly available. Data are however available from the authors upon reasonable request and with permission of Perined.

\section{Authors' contributions}

JoK and AS wrote the manuscript, all other authors (EdM, AvD, JuK, AB, BWM FFPHAV and JVD) critically revised the drafts of the manuscript and approved the final version of the manuscript. AvD works for Perined and provided the database. EdM and JvD supervised all tasks.

\section{Ethics approval and consent to participate}

No ethical approval was needed according to the Dutch Central Committee of Human Research, because of the retrospective cohort study.

\section{Consent for publication}

Not applicable.

\section{Competing interests}

$\mathrm{JVD}$ is a member of the editorial board (associate editor) of the BMC Pregnancy and Childbirth. All other authors declare that they have no competing interests.

\section{Publisher's Note}

Springer Nature remains neutral with regard to jurisdictional claims in published maps and institutional affiliations.

\section{Author details}

'Department of Obstetrics and Gynaecology, Radboud University Medical Center, Geert Grooteplein Zuid 10, 6523, GA, Nijmegen, the Netherlands. ${ }^{2}$ Department of Obstetrics and Gynaecology, Amsterdam University Medical Centers, Amsterdam, the Netherlands. ${ }^{3}$ Perined, Utrecht, the Netherlands. ${ }^{4}$ Department of Obstetrics and Gynaecology, Monash University, Clayton, VIC, Australia.

Received: 4 January 2018 Accepted: 9 August 2018

Published online: 20 September 2018

\section{References}

1. Vayssiere C, Haumonte JB, Chantry A, Coatleven F, Debord MP, Gomez C, Le Ray C, Lopez E, Salomon LJ, Senat MV, et al. Prolonged and post-term pregnancies: guidelines for clinical practice from the French College of Gynecologists and Obstetricians (CNGOF). Eur J Obstet Gynecol Reprod Biol. 2013;169(1):10-6.

2. Zeitlin J, Blondel B, Alexander S, Breart G, Group P. Variation in rate of postterm birth in Europe: reality or artefact? BJOG. 2007:114(9): 1097-103.

3. Whitworth J. Data sharing: reaching consensus. Bull World Health Organ 2010;88(6):467-8

4. Carbonne B, Sentilhes L, Vayssiere C. Intra uterine growth retardation: guidelines for clinical practice--introduction. J Gynecol Obstet Biol Reprod (Paris). 2013;42(8):868-9.

5. Roos N, Sahlin L, Ekman-Ordeberg G, Kieler H, Stephansson O. Maternal risk factors for postterm pregnancy and cesarean delivery following labor induction. Acta Obstet Gynecol Scand. 2010;89(8):1003-10.

6. Gulmezoglu AM, Crowther CA, Middleton P, Heatley E. Induction of labour for improving birth outcomes for women at or beyond term. Cochrane Database Syst Rev. 2012;6:CD004945.
7. Hussain AA, Yakoob MY, Imdad A, Bhutta ZA. Elective induction for pregnancies at or beyond 41 weeks of gestation and its impact on stillbirths: a systematic review with meta-analysis. BMC Public Health. 2011; 11(Suppl 3):S5.

8. Ingemarsson I, Kallen K. Stillbirths and rate of neonatal deaths in 76,761 postterm pregnancies in Sweden, 1982-1991: a register study. Acta Obstet Gynecol Scand. 1997;76(7):658-62.

9. Foundation Perinatal Audit in The Netherlands: Term mortality 2010-2012. Perinatal audit on track [in Dutch]; 2014.

10. American College of Obstetricians and Gynaecologists (ACOG), practice bulletin no. 146: management of late-term and postterm pregnancies. Obstet Gynecol 2014, 124(2 Pt 1):390-396.

11. Nederlandse Vereniging voor Obstetrie en Gynaecologie (NVOG): Dutch Society of Obstetrics and Gynaecology: Richtlijn Serotiniteit / 'Guideline postterm pregnancy'. 2007.

12. Kortekaas JC, Bruinsma A, Keulen JK, van Dillen J, Oudijk MA, Zwart JJ, Bakker JJ, de Bont D, Nieuwenhuiize M, Offerhaus PM, et al. Effects of induction of labour versus expectant management in women with impending post-term pregnancies: the 41 week - 42 week dilemma. BMC Pregnancy Childbirth. 2014;14:350.

13. Bergsjo P, Bakketeig LS, Langhoff-Roos J. The development of perinatal audit: 20 years' experience. Acta Obstet Gynecol Scand. 2003;82(9):780-8.

14. De Reu PA, Oosterbaan HP, Smits LJ, Nijhuis JG. Perinatal mortality in preterm births: an analysis of causes, presence of substandard care and avoiding mortality in three Dutch regions. J Perinat Med. 2011;39(5):499-505.

15. Richardus JH, Graafmans WC, Verloove-Vanhorick SP, Mackenbach JP, EuroNatal international audit $P$, EuroNatal working $G$. Differences in perinatal mortality and suboptimal care between 10 European regions: results of an international audit. BJOG. 2003;110(2):97-105.

16. Dunn PM, Mcllwaine G. Perinatal audit. A report produced for the European Association of Perinatal Medicine. New York: Parthenon; 1996

17. Hey EN, Lloyd DJ, Wigglesworth JS. Classifying perinatal death: fetal and neonatal factors. Br J Obstet Gynaecol. 1986;93(12):1213-23.

18. Wigglesworth JS. Classification of perinatal deaths. Soz Praventivmed. 1994; 39(1):11-4.

19. Gardosi J, Kady SM, McGeown P, Francis A, Tonks A. Classification of stillbirth by relevant condition at death (ReCoDe): population based cohort study. BMJ. 2005:331(7525):1113-7.

20. Chan A, King JF, Flenady V, Haslam RH, Tudehope DI. Classification of perinatal deaths: development of the Australian and New Zealand classifications. J Paediatr Child Health. 2004;40(7):340-7.

21. Perined: Manual: Classification of mortality and morbidity at a perinatal audit/Mortaliteit en morbiditeitsclassificatie bij perinatale audit. 2017.

22. Gordijn SJ, Korteweg FJ, Erwich JJ, Holm JP, van Diem MT, Bergman KA Timmer A. A multilayered approach for the analysis of perinatal mortality using different classification systems. Eur J Obstet Gynecol Reprod Biol. 2009:144(2):99-104.

23. Eskes M, Waelput AJM, Erwich JJHM, et al. Term perinatal mortality audit in the Netherlands 2010-2012: a population-based cohort study. BMJ Open. 2014:4:e005652. https://doi.org/10.1136/bmjopen-2014-005652.

24. van Diem MT, Timmer A, Bergman KA, Bouman K, van Egmond N, Stant DA, Ulkeman LH, Veen WB, Erwich JJ. The implementation of unit-based perinatal mortality audit in perinatal cooperation units in the northern region of the Netherlands. BMC Health Serv Res. 2012;12:195.

25. Vincent $C$. Understanding and responding to adverse events. N Engl J Med. 2003;348(11):1051-6.

26. Stichting Perinatale Registratie Nederland. Perinatale Zorg in Nederland 2010. [Netherlands perinatal registry. Perinatal Care in the Netherlands 2010]. Stichting Perinatale Registratie Nederland: Utrecht; 2013.

27. Stichting Perinatale Registratie Nederland. Perinatale Zorg in Nederland 2011. [Netherlands perinatal registry. Perinatal Care in the Netherlands 2011]. Stichting Perinatale Registratie Nederland: Utrecht; 2013.

28. Stichting Perinatale Registratie Nederland: Perinatale Zorg in Nederland 2012. [Netherlands Perinatal Registry. Perinatal Care in the Netherlands 2012]. 2013

29. Robertson L, Knight H, Prosser Snelling E, Petch E, Knight M, Cameron A Alfirevic Z. Each baby counts: national quality improvement programme to reduce intrapartum-related deaths and brain injuries in term babies. Semin Fetal Neonatal Med. 2017;22(3):193-8.

30. World Health Organization (WHO): Making every baby count: audit and review of stillbirths and neonatal deaths, 2016. 
31. Kerber K, Mathai M, Lewis G, Flenady V, Erwich JJ, Segun T, Aliganyira P Abdelmegeid A, Allanson E, Roos N, et al. Counting every stillbirth and neonatal death through mortality audit to improve quality of care for every pregnant woman and her baby. BMC Pregnancy Childbirth. 2015;15(Suppl 2):S9.

32. Wojcieszek AM, Reinebrant HE, Leisher SH, Allanson E, Coory M, Erwich JJ, Froen JF, Gardosi J, Gordijn S, Gulmezoglu M, et al. Characteristics of a global classification system for perinatal deaths: a Delphi consensus study. BMC Pregnancy Childbirth. 2016;16:223.

33. de Bernis L, Kinney MV, Stones W, Ten Hoope-Bender P, Vivio D, Leisher SH, Bhutta ZA, Gulmezoglu M, Mathai M, Belizan JM, et al. Stillbirths: ending preventable deaths by 2030. Lancet. 2016;387(10019):703-16.

34. Flenady V, Wojcieszek AM, Middleton P, Ellwood D, Erwich JJ, Coory M, Khong TY, Silver RM, Smith GC, Boyle FM, et al. Stillbirths: recall to action in high-income countries. Lancet. 2016;387(10019):691-702.

35. Aminu M, Bar-Zeev S, van den Broek N. Cause of and factors associated with stillbirth: a systematic review of classification systems. Acta Obstet Gynecol Scand. 2017:96(5):519-28.

36. Allanson ER, Tuncalp GJ, Pattinson RC, Vogel JP, Erwich J, Flenady VJ, Froen JF, Neilson J, Quach A, et al. Giving a voice to millions: developing the WHO application of ICD-10 to deaths during the perinatal period: ICD-PM. BJOG. 2016;123(12):1896-9.

37. International Stillbirth Alliance Collaborative for Improving Classification of Perinatal D, Flenady V, Wojcieszek AM, Ellwood D, Leisher SH, Erwich J, Draper ES, EM MC, Reinebrant HE, Oats J, et al. Classification of causes and associated conditions for stillbirths and neonatal deaths. Semin Fetal Neonatal Med. 2017:22(3):176-85.

38. Mandujano A, Waters TP, Myers SA. The risk of fetal death: current concepts of best gestational age for delivery. Am J Obstet Gynecol. 2013;208(3):207 e201-8

39. Rosenstein MG, Cheng YW, Snowden JM, Nicholson JM, Caughey AB. Risk of stillbirth and infant death stratified by gestational age. Obstet Gynecol. 2012;120(1):76-82.

40. Rainaldi MA, Perlman JM. Pathophysiology of birth asphyxia. Clin Perinatol. 2016:43(3):409-22.

41. Mecacci F, Serena C, Avagliano L, Cozzolino M, Baroni E, Rambaldi MP, Simeone S, Castiglione F, Taddei GL, Bulfamante G. Stillbirths at term: case control study of risk factors, growth status and placental histology. PLoS One. 2016;11(12):e0166514.

42. Berglund S, Grunewald C, Pettersson H, Cnattingius S. Risk factors for asphyxia associated with substandard care during labor. Acta Obstet Gynecol Scand. 2010;89(1):39-48.

43. Divon MY, Haglund B, Nisell H, Otterblad PO, Westgren M. Fetal and neonatal mortality in the postterm pregnancy: the impact of gestational age and fetal growth restriction. Am J Obstet Gynecol. 1998;178(4):726-31.

44. Boers KE, Vijgen SM, Bijlenga D, van der Post JA, Bekedam DJ, Kwee A, van der Salm PC, van Pampus MG, Spaanderman ME, de Boer K, et al. Induction versus expectant monitoring for intrauterine growth restriction at term: randomised equivalence trial (DIGITAT). BMJ. 2010;341:C7087.

45. Berglund S, Pettersson $\mathrm{H}$, Cnattingius $\mathrm{S}$, Grunewald $\mathrm{C}$. How often is a low Apgar score the result of substandard care during labour? BJOG. 2010; 117(8):968-78.

46. Berglund S, Grunewald C, Pettersson H, Cnattingius S. Severe asphyxia due to delivery-related malpractice in Sweden 1990-2005. BJOG. 2008;115(3):316-23.

47. Batlle L, Guyard-Boileau B, Thiebaugeorges O, Caubisens A, Vaquie MF, Thiery F, Parant O, Vayssiere C. Analysis of the evitability of intrapartum asphyxia with a peers review. J Gynecol Obstet Biol Reprod (Paris). 2013; 42(6):550-6.

48. Rhose S, Heinis AM, Vandenbussche F, van Drongelen J, van Dillen J. Interand intra-observer agreement of non-reassuring cardiotocography analysis and subsequent clinical management. Acta Obstet Gynecol Scand. 2014; 93(6):596-602.

49. van Diem MT, Timmer A, Gordijn SJ, Bergman KA, Korteweg FJ, Ravise J, Vreugdenhil E, Erwich JJ. Classification of substandard factors in perinatal care: development and multidisciplinary inter-rater agreement of the Groningen-system. BMC Pregnancy Childbirth. 2015;15:215.

Ready to submit your research? Choose BMC and benefit from:

- fast, convenient online submission

- thorough peer review by experienced researchers in your field

- rapid publication on acceptance

- support for research data, including large and complex data types

- gold Open Access which fosters wider collaboration and increased citations

- maximum visibility for your research: over $100 \mathrm{M}$ website views per year

At BMC, research is always in progress.

Learn more biomedcentral.com/submissions 